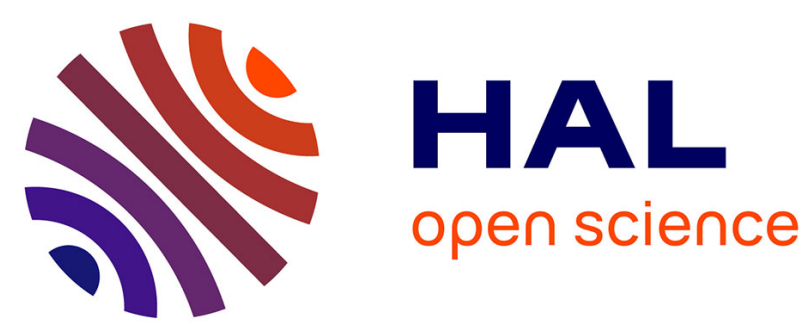

\title{
FAME : A new beamline for X-ray absorption investigations of very-diluted systems of environmental, material and biological interests
}

Olivier Proux, X Biquard, Eric Lahera, Jean-Jacques Menthonnex, Alain

Prat, Olivier Ulrich, Yvonne Soldo, Patrick Trévisson, G Kapoujyan, G Perroux, et al.

\section{To cite this version:}

Olivier Proux, X Biquard, Eric Lahera, Jean-Jacques Menthonnex, Alain Prat, et al.. FAME: A new beamline for X-ray absorption investigations of very-diluted systems of environmental, material and biological interests. Physica Scripta, 2005, 115, pp.970-973. 10.1238/Physica.Topical.115a00970 . hal-01223669

\section{HAL Id: hal-01223669 \\ https://hal.science/hal-01223669}

Submitted on 3 Nov 2015

HAL is a multi-disciplinary open access archive for the deposit and dissemination of scientific research documents, whether they are published or not. The documents may come from teaching and research institutions in France or abroad, or from public or private research centers.
L'archive ouverte pluridisciplinaire HAL, est destinée au dépôt et à la diffusion de documents scientifiques de niveau recherche, publiés ou non, émanant des établissements d'enseignement et de recherche français ou étrangers, des laboratoires publics ou privés. 


\title{
FAME : A new beamline for X-ray absorption investigations of very-diluted
} systems of environmental, material and biological interests

O. Proux, ${ }^{1 *}$ X. Biquard, ${ }^{2}$ E. Lahera, ${ }^{1}$ J-J. Menthonnex, ${ }^{1}$ A. Prat, ${ }^{3}$ O. Ulrich, ${ }^{2}$ Y. Soldo, ${ }^{4}$ P. Trévisson, ${ }^{5}$ G. Kapoujyan, ${ }^{5}$ G. Perroux, ${ }^{5}$ P. Taunier, ${ }^{3}$ D. Grand, ${ }^{5}$ P. Jeantet, ${ }^{5}$ M. Deleglise, ${ }^{5}$ J-P. Roux ${ }^{5}$ and J-L. Hazemann ${ }^{3}$

${ }^{1}$ Laboratoire de Géophysique Interne et Tectonophysique, UMR CNRS / Université Joseph Fourier, 1381, rue de la Piscine, Domaine Universitaire, F-38400 Saint-Martin-D'Hères, France

${ }^{2}$ CEA/Grenoble, DRFMC/SP2M/NRS, 17 avenue des Martyrs, F-38054 Grenoble Cedex 9

${ }^{3}$ Laboratoire de Cristallographie, CNRS, 25 avenue des Martyrs, BP 166, F-38042 Grenoble cedex 9, France

${ }^{4}$ Laboratoire d'Electrochimie et de Physico-chimie des Matériaux et des Interfaces, UMR 5631 CNRS/INPG/UJF, 1130 rue de la Piscine, Domaine Universitaire, BP 75, F-38402 St. Martin d'Hères, France

${ }^{5}$ Service Etudes et Réalisation d'Appareillages Scientifiques, CNRS, 25 avenue des Martyrs, BP 166, F-38042 Grenoble cedex 9, France

\begin{abstract}
FAME is the French Absorption spectroscopy beamline in Material and Environmental sciences at the ESRF (France), operational since September 2002. Technically speaking, the source is a $0.85 \mathrm{~T}$ bending magnet and the main optical element is a two-crystals monochromator using either $\operatorname{Si}(111)$ or $\operatorname{Si}(220)$ monocrystals so that the available energy ranges from 4 to $40 \mathrm{keV}$. The first crystal is liquid nitrogen cooled in order to avoid the thermal bump and thus preserve the energy resolution. The second crystal is dynamically bent during the energy scan in order to focalize the beam in the horizontal plane. Two bendable mirrors are located before and after the monochromator, for a beam-collimation (to optimize the energy resolution) and a vertical focalization, respectively. During scans, the beam on the sample is kept constant in position and size (around $150 \times 200 \mu \mathrm{m}^{2}, \mathrm{~V} \times \mathrm{H}$ ). The high flux on the sample combined with the sensitivity of our 30-elements fluorescence detector allow to decrease the detection limit down to $10 \mathrm{ppm}$ or around less than a monolayer. Moreover, quick-EXAFS acquisition is operational: the acquisition time may be reduced down to $30 \mathrm{~s}$.

PACS: $61.10 . \mathrm{Ht}, 07.85 . \mathrm{Qe}, 41.50 .+\mathrm{h}$

*Corresponding author : proux@grenoble.cnrs.fr
\end{abstract}




\section{Introduction}

FAME is the French Absorption spectroscopy beamline in Material and Environmental sciences at the ESRF (France), in operation since September 2002. This beamline is one of the four french Collaborating Research Group (CRG) beamlines.

The possibility of determining the local structure of elements at very low concentration is one of the most important and appealing feature of X-ray Absorption Spectroscopy. This technique gathers a large and growing community of users comprising environmentalists, electrochemists, biologists, material and catalysis scientists. That's why it was decided to provide this community with a dedicated beamline, thus extending available beamtime for absorption experiments. The XAS-station of CRG-IF was then transferred to the CRG-FAME beamline and a new optical line was designed and built. The project was supported by a number of laboratories from the Centre National de la Recherche Scientifique (CNRS), the Commissariat à l'Energie Atomique (CEA) and the Universities of Grenoble and Lyon. Given the high implication of regional laboratories, a partial financing from "Région Rhone-Alpes" has been moreover obtained. 50 to $60 \%$ of the beam time will be dedicated to environmental and earth science studies, the remainder will be used for material, chemical and biological applications. We give herein a brief description of the beamline, the various optical elements and the experimental apparatus. More technical details and pictures can be found on the FAME website [1].

\section{General features}

The FAME beamline is located on a $0.85 \mathrm{~T}$ bending magnet (BM) of the ESRF storage ring working at $6 \mathrm{GeV}$. The beamline design has been optimized in order to accept the $2 \mathrm{mrad}$ horizontal and $0.3 \mathrm{mrad}$ vertical divergences delivered by the $\mathrm{BM}$, i.e. its full fan. The magnification ratio (source to monochromator distance $v s$ monochromator to sample distance) has been chosen to be 3 to maximize the monochromator transmission. The flux on the sample is maximized when the beam is horizontally focused bending the $2^{\text {nd }}$ crystal of the monochromator [2].

The basic optical design of FAME is shown in Fig. 1. The main optical element is the monochromator, located between two grazing-incidence mirrors. Due to the Rhodium coating of the mirrors, such a configuration is suitable for studies at energies lower than $22 \mathrm{keV}$. The beamline can also operate in a mirror-free configuration, extending the energy limit close to the BM cutoff. The photon energies available on FAME range then from 4 to $40 \mathrm{keV}$ : all the 
elements with an atomic number higher than 20 (Calcium) can be studied either at the $\mathrm{K}$ or $\mathrm{L}$ or both edges.

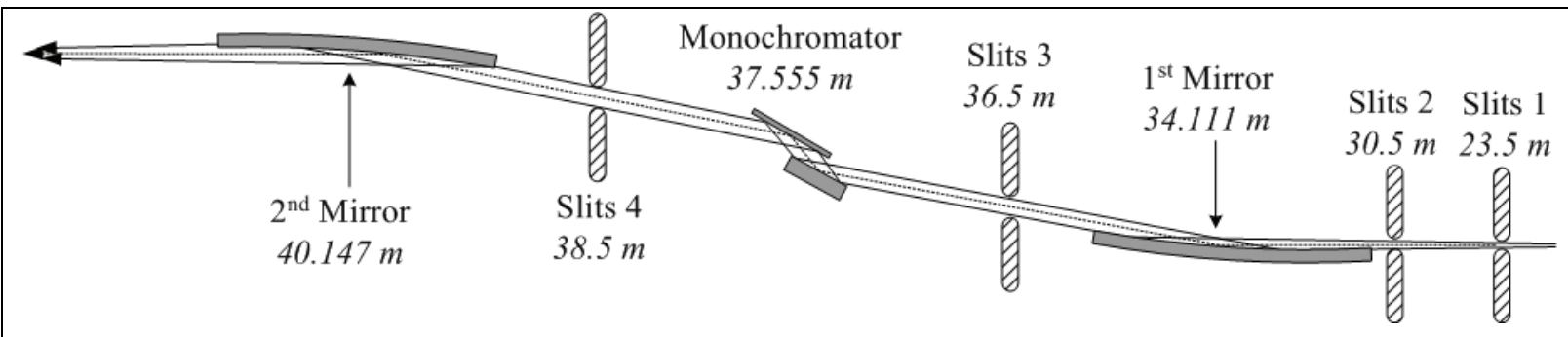

Figure 1: Schematic diagram of the CRG-FAME beamline optic elements (side view). The distances from the $\mathrm{BM}$ source of the various elements are indicated (the sample is located at $50.065 \mathrm{~m}$ ).

In order to define the size and the optic axis of the beam, two pairs of vertical and horizontal micrometric slits are located at $23.5 \mathrm{~m}$ (slits 1) and $30.5 \mathrm{~m}$ (slits 2) from the source. To decorrelate the beamline from eventual variations in direction or position of the X-ray source, the water-cooled tungsten carbide slits are located before our optical elements The distance between these slits was taken as large as possible in order to precisely define the beam. Other slits are located after the first mirror (slits 3 ) and after the monochromator (slits 4), to remove the scattered beams induced by the optical elements.

FAME was designed in order to have the maximum flux on the sample, especially at low energies. Only two Be windows are on the beam path, a first $500 \mu \mathrm{m}$ Be window between the storage ring and the beamline and a second one at the end of the beamline, just before the sample. The vacuum device was conceived using differential pumping between the different elements, in order to have a smooth transition between the $1 \sim 210^{-9}$ mbar range achieved in the mirrors chambers (ionic pumps) and the $2 \sim 510^{-8}$ mbar range achieved in the monochromator (turbo pump linked to a cryo-pumping effect).

\section{Optical elements}

\subsection{First mirror}

The first optic component installed on FAME is a horizontal bendable mirror that deflects vertically the beam, manufactured by IRELEC (France). The mirror is a monocrystalline Silicium ingot with a $50 \mathrm{~nm}$ Rhodium coating (manufactured by SAGEM - REOSC S.A., France). Transversal and longitudinal inclinations of the mirror use goniometric cradles. They are completely separated from height and bender adjustment: all the movements are then uncorrelated. The mirror can be bended using a single jack bender (symmetric bending) and 
its position (height, incidence and tilt angles) can be adjusted independently from the vacuum vessel. The white beam incidence angle on the mirror can vary in the 3-7 mrad range. The cutoff energy ranges then from 9 to $22 \mathrm{keV}$.

The main functions of the $1^{\text {st }}$ mirror are the following:

- collimation of the incident beam to adapt its vertical divergence to the $1^{\text {st }}$ crystal of the monochromator, in order to optimize the energy resolution of the monochromator,

- reduction of the high energy harmonics' intensity,

- reduction of the heat load on the monochromator.

Optical tests were performed in the ESRF metrology laboratory with a Long Trace Profiler [3] and a PROMAP 512 apparatus, in order to check the radius of curvature, the slope error, profiles and shape errors and the rugosity. The obtained values are gathered in table 1. With respect to the large size of the polished surface, the measured slope errors and roughness are really good.

The cooling device of the mirror has been designed in order to limit as much as possible the transmission of vibrations coming from the beamline to the reflecting surface. For this, the cooling apparatus is linked to the cooled part of the mirror via a liquid metallic alloy. The vibrations induced by the cold water circulation are then damped by the liquid alloy. Moreover, the cooling water temperature is continuously adjusted in order to obtain a $2{ }^{\circ} \mathrm{C}$ gradient of temperature for the water between the entrance and the exit of the mirror chamber. The slope error of the mirror is then as low as possible .

\begin{tabular}{ccc}
\hline Mirrors characteristics & $\mathbf{1}^{\text {st }}$ mirror & $\mathbf{2}^{\text {nd }}$ mirror \\
\hline optical and geometrical Lengths $(\mathrm{mm})$ & $1150-1350$ & $1250-1450$ \\
\hline optical and geometrical Widths $(\mathrm{mm})$ & $80-110$ & $80-110$ \\
\hline Thickness $(\mathrm{mm})$ & 54 & 35 \\
\hline minimum Bending Radius $(\mathrm{km})$ & 38 & 10 \\
\hline maximum Bending Radius $(\mathrm{km})$ & 3.4 & 1.0 \\
\hline mean and central rms slope error $(\mu \mathrm{rad})$ & $2.4-1.8$ & $3.0-2.5$ \\
\hline mean rms roughness $(\AA)$ & $1.4 \pm 0.3$ & $2.6 \pm 1.0$ \\
\hline
\end{tabular}

Table 1: Mirrors main characteristics

\subsection{Monochromator}

A two-crystals monochromator is located after the first collimating mirror. Its design and construction were performed by our team. The main numerical characteristics are gathered in table 2. The obtained characteristics, as checked by metrology at the ESRF [4], are always 
better than expected. Two kinds of monocrystals are available, $\operatorname{Si}(111)$ and $\operatorname{Si}(220)$, well adapted in the energy ranges 4-25 keV and 5-40 keV, respectively. Moreover, the monochromator can be used in two configurations: variable exit (pseudo-channelcut mode) and fixed exit (constant vertical position of the beam after the monochromator).

The first crystal is liquid nitrogen cooled at around $110 \mathrm{~K}$ to avoid thermal bump. At this temperature, thermal conductivity of silicon is maximum and its thermal expansion is almost zero. The high heat load of the incoming beam $(300 \mathrm{~W}$ at the maximum, in the mirror-free configuration) is removed using flexible copper wires, avoiding vibrations. The second crystal is dynamically curved (from $1 \mathrm{~m}$ to $\infty$ ) during XAFS energy scan in order to keep the beam focused on the sample in the horizontal plane [5]. The horizontal FWHM size of the spot is always below $300 \mu \mathrm{m}$, even at low energies (small radius of curvature of the $2^{\text {nd }}$ crystal). Figure 2 shows an example of focused beam shape obtained at $7 \mathrm{keV}$.
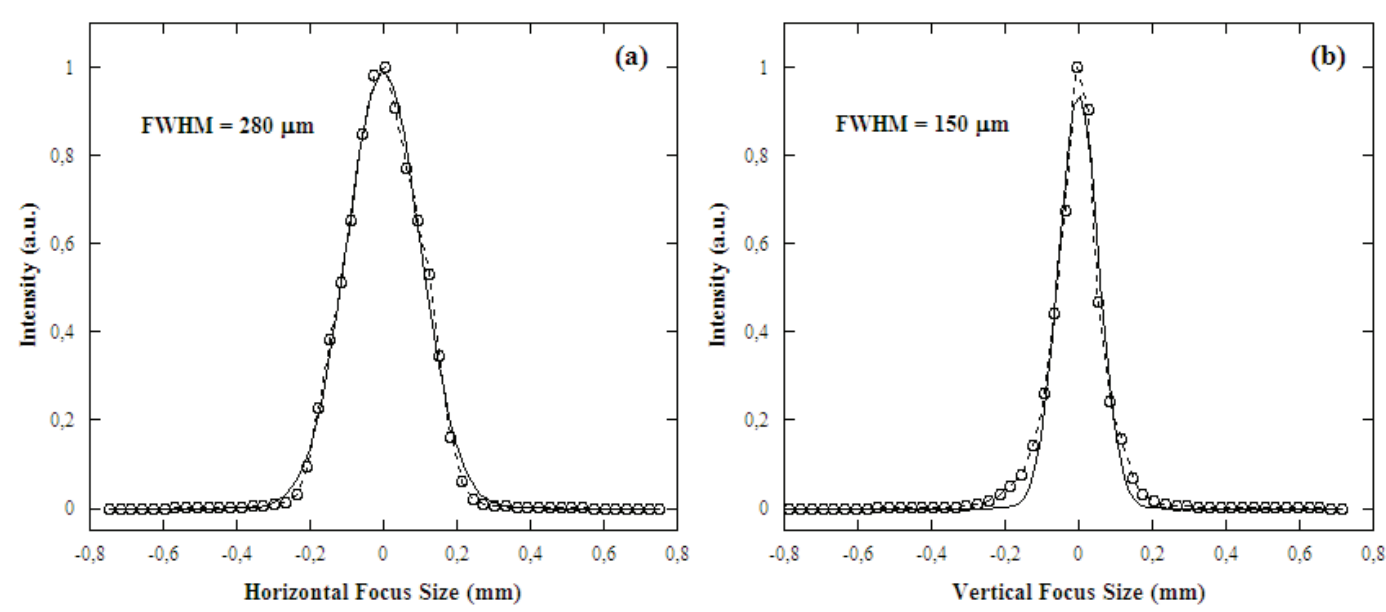

Figure 2: Focused beam shapes in the horizontal (a) and vertical (b) planes, measured (open circles and dashed line) and superimposed Gaussian fit (solid line). The measurements have been performed at $7 \mathrm{keV}$ using $\mathrm{Si}(111)$ monochromator crystals, with a 7 mrad incidence angles for the mirrors and using the entire vertical and horizontal divergences.

The axis of the monochromator is equipped with a RON905 encoder (resolution: $1 / 1000^{\circ}$ ), linked to an interpolator box (1/800). The theoretical resolution is then $1 / 80000^{\circ}$ while the measured resolution is $1 / 40000^{\circ}$ (Tab. 2). The axis brushless motor is ensured with a McLennan PM600 motor controller.

The monochromator can work in two configurations: in the step-by-step mode (classical EXAFS) and in the continuous one (quick EXAFS). In both cases, the angle movement during the energy scan operates simultaneously with the adjustments 
1) of the $2^{\text {nd }}$ crystal curvature

2) of the parallelism between the two crystals, allowing the maintain at the maximum of the $2^{\text {nd }}$ crystal's rocking curve

3) of the EXAFS table height (see $\S 4)$.

\begin{tabular}{ccc}
\hline Monochromator characteristics & wanted & obtained \\
\hline axis angular resolution & $1 / 10000^{\circ}$ & $1 / 40000^{\circ}$ \\
\hline $\begin{array}{c}\text { maximum angular deviation of the axis during } \\
\text { rotation }\end{array}$ & $5 \mu \mathrm{rad}$ on $5^{\circ} \mathrm{range}$ & $5 \mu \mathrm{rad}$ on $40^{\circ}$ range \\
\hline $2^{\text {nd }}$ crystal translation precision & $0.1 \mu \mathrm{m}$ & $0.1 \mu \mathrm{m}$ \\
\hline monochromator translation & $65 \pm 0.05 \mathrm{~mm}$ & $100 \pm 0.001 \mathrm{~mm}$ \\
\hline $\begin{array}{c}\text { maximum angular deviation of the } \\
\text { monochromator during translation }\end{array}$ & $\begin{array}{c}5 \mu \mathrm{rad} \text { on } 65 \mathrm{~mm} \\
\text { translation }\end{array}$ & $\begin{array}{c}5 \mu \mathrm{rad} \text { on } 100 \mathrm{~mm} \\
\text { translation }\end{array}$ \\
\hline
\end{tabular}

Table 2: Monochromator main characteristics

\subsection{Second mirror}

The $2^{\text {nd }}$ mirror is located in the monochromatic part of the beamline. Its objectives are to eliminate the remaining harmonics and mainly to focus the beam in the vertical plane on the sample. The reflective angle is always equal to the one of the $1^{\text {st }}$ mirror, in order to obtain a perfect horizontal beam after it. Compared to the $1^{\text {st }}$ mirror, the $2^{\text {nd }}$ one is longer and thinner (Tab. 1), in order to reach smaller radius of curvature. Moreover, this high length allows to keep its height fixed during an energy scan even if output height of the monochromator varies (variable exit mode). The position of the beam on the mirror can then slightly change without being close to the edges.

The vertical size of the beam on the sample can then be adjust between 100 to $500 \mu \mathrm{m}$ (example Fig. 2.b), with respect to the kind of studied samples (mainly with respect to their homogeneity).

\section{Experiment apparatus}

X-ray Absorption Spectroscopy (XAS) apparatus on FAME is composed of the previously existing elements on the IF beamline XAS station. Position of the experimental table (height, transversal translation and rotation) can be controlled so that the beam position on the sample remains constant. The height position (precision about $1 \mu \mathrm{m}$ ) is dynamically adjusted during an EXAFS scan, allowing the beam position on the sample to remain constant. 
The sample is located on a "goniometric head" sample holder. Different movements are motorized: transverse and vertical translations, rotation $\left(360^{\circ}\right)$ and goniometric cradles $\left( \pm 7^{\circ}\right)$. Different classical environment can be mounted on the goniometric head: 1) basic vacuum chamber (for low energy experiment), 2) liquid nitrogen and 3) liquid helium cryostats.

Moreover, the experimental environment can be easily adapted to the users' need and can accept several apparatus elaborated in other laboratories. This is especially suitable for in situ studies, electrochemistry cell [6], catalysis oven in gaseous atmosphere [7], high temperature and high pressure cells $[8,9] \ldots$

Three kind of detectors are used on FAME. The transmitted signals are measured with Si diodes collecting the beam scattered by kapton foils. The fluorescence measurements are performed using a 30-elements solid germanium Canberra energy-resolved detector. This detector is very well adapted for studies on highly diluted samples or thin films. For a 125 and $500 \mathrm{~ns}$ shaping time, its energy resolution is about 300 and $250 \mathrm{eV}$ and the maximum allowed count rate by element is about 100000 and 30000 counts/s, respectively. Finally, an electron detector (analysis temperature from 77 to 300K) working on a helium atmosphere (Conversion Electron mode) is also well-suitable for thin films studies.

\section{Perspectives and conclusion}

We have described the new CRG-FAME XAS beamline in operation at the ESRF (France) since september 2002. The main optic element is a two-crystals monochromator equipped with two kinds of monocrystals, $\operatorname{Si}(111)$ and $\operatorname{Si}(220)$. The available energy ranges from 4 to $40 \mathrm{keV}$. The first crystal is liquid nitrogen cooled in order to avoid the thermal bump and thus to preserve the energy resolution. The second crystal is dynamically bended during the energy scan in order to focalize the beam in the horizontal plane. Two bendable mirrors are located before and after the monochromator, for a beam-collimation (optimisation of the energy resolution) and a vertical focalization. The size (around $250 \times 150 \mu \mathrm{m}^{2}$ ) and the position of the beam on the sample is then kept constant during scans. The high flux on the sample combined with the sensitivity of the fluorescence detector allow to decrease the detection limit down to $10 \mathrm{ppm}$ and the acquisition time of a spectrum to around 30s (QEXAFS mode). A microfocalisation apparatus (Kirkpatrick-Baez) will allow to decrease the size of the beam, $20 \times 20$ $\mu \mathrm{m}^{2}$ with the full flux, $1 \times 1 \mu \mathrm{m}^{2}$ with slits. Preliminary micro-XAS experiments have been performed: construction of the optic elements will be achieved this year.

\section{Acknowledgements}


The authors wish to acknowledge the help of the ESRF technical staff and support groups and in particular Alonso Garcia C. and Patrunau V. (handling), Vassalli J.P. and Villermet P. (monochromator crystals realisation), Rommevaux A. (mirrors metrology), Van Der Kleij H.P. (monochromator metrology), the alignment group, especially Levet N. and Lefevre C. and all the people from the CRG liaison, Dettona E., Kaprolat A., Bombana J., Kilvington I., Glueckert M., Rigolet M. and Clément V. Thanks is also given to all the users who helped us for the beamline commissioning.

\section{References}

[1] http://www.esrf.fr/UsersAndScience/Experiments/CRG/BM30B/

[2] Hrdy J., Rev. Sci. Instrum., 65 2147-2148 (1994)

[3] Hignette O. and Rommevaux A., Proceedings SPIE 2856 314-322 (1996)

[4] for more technical details see the webpage of the Precision Engineering Laboratory : http://www.esrf.fr/UsersAndScience/Experiments/TBS/MechanicsService/PELab/

[5] Hazemann J.L., Nayouf K. and de Bergevin F., Nucl. Instr. and Meth. B, 97 547-550 (1995)

[6] Soldo Y. et al., Electroch. Acta 47, 3081-3091(2002)

[7] Geantet C. et al., Catalysis Letters, 73, 95-98 (2001)

[8] Pokrovski G.S. et al., Geochim. Cosmochim. Acta, 66 3453-3480 (2002), 66 4203-4222 (2002)

[9] Simonet V. et al., J. Chem. Phys., 116 2997-3006 (2002) 